\title{
Cartilha para Civilizar
}

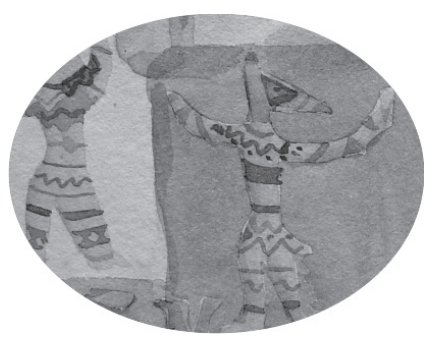

Otoni Moreira de Mesquita*6

\section{Resumo}

Este ensaio pretende estabelecer uma discussão preliminar sobre tentativas de promover mudanças na paisagem urbana e nos traços culturais da cidade de Manaus, nas quatro primeiras décadas da segunda metade do século XIX. A partir do pressuposto de que somente após a instalação da província do Amazonas em 1. ${ }^{\circ}$ de janeiro de 1852 é que se constituiu um corpo administrativo e recursos capazes de promover algumas intervenções na imagem da cidade. Entretanto, deve-se notar que os parcos recursos disponíveis não permitiam um planejamento apurado. Logo, as ações da administração local se limitavam a um conjunto de intervenções fragmentadas e sem continuidade, tendo de priorizar as necessidades mais urgentes e as determinações procedentes da corte. Contudo, estas características não deixam de definir um perfil das políticas públicas adotadas na região.

Palavras-chave: Manaus. Urbanismo. Século XIX.

\begin{abstract}
This essay aims at establishing a preliminary discussion of attempts to promote changes in the urban landscape and cultural features of the city of Manaus, in the first four decades of the second half of the nineteenth century. Assuming that only after the installation of the province of Amazonas on 1 January 1852 is that it was an administrative body and features a number of interventions that promote the image of the city. However, it should be noted that the scarce resources available
\end{abstract}

\footnotetext{
"Doutorado em História Social pela Universidade Federal Fluminense, Brasil(2005). Professor Adjunto da Universidade Federal do Amazonas, Brasil. Otoni_mesquita@hotmail.com
} 
did not permit an accurate planning. Therefore, the actions of local government were limited to a set of fragmented interventions and not continued, having to prioritize the most urgent needs and the determination of the court proceeding. However, these characteristics do not allow to define a profile of public policies adopted in the region.

Keywords: Manaus. Urban. Nineteenth century.

Antes de iniciar a discussão proposta devemos alertar para a limitação conceitual contida no título desse ensaio, que sugere promover a civilização por meio de uma cartilha. Por outro lado, não podemos deixar de fazer referência à língua como um dos maiores patrimônios de uma cultura e lembrar que até algumas décadas atrás o ensino da língua nacional se fazia através de cartilhas, cuja vigência passava pelas mãos de gerações com o mesmo vigor. A cartilha fornecia noções de um aprendizado e permitia penetrar no universo do conhecimento, estabelecia rígidas hierarquias e valores, que perderam a validade perante as inovadoras propostas que se superpõe a cada semestre escolar.

A escolha por uma determinada cartilha é uma opção para ler e compreender o mundo. Ainda que nem sempre a forma de seu conteúdo seja explícita, ela revela coerência e comprometimento com um conjunto de ideias que regem a sociedade. Mesmo que constituída por meio de convenções, em geral, suas orientações tendem a reforçar os interesses de um conjunto social, político e econômico, que determina as prioridades e as ações pra promover o desenvolvimento real de uma determinada sociedade, em um dado momento.

Assim, pretendemos assinalar o papel doutrinário do aparato de recursos utilizados pela administração pública, ressaltando-o como um conjunto de convenções passíveis de serem ordenadas e formalizadas no sentido de reforçar as ideias e tendências de determinado grupo e o intuito de impor um processo de civilização.

$\mathrm{Na}$ realidade, pretendemos abordar algumas tentativas adotadas pelo Estado, através da administração provincial, no sentido de modificar as condições locais e estabelecer uma cidade e uma sociedade mais de acordo com os parâmetros das tradições da civilização europeia. Notando que tais estratégias geraram encontros e desencontros no cotidiano da pequena cidade 
e provocaram mudanças. Por um lado, havia um esforço para promover o branqueamento dos costumes e das representações nativas em busca de maior uniformidade. Por outro lado, havia uma resistência natural em conservar antigos hábitos e tradições, que resistiam mesmo inconscientemente, notando-se que muitas vezes, as mudanças propostas não passavam de convenções vazias e sem sentido, pois se encontravam distantes da realidade e das necessidades locais.

Em virtude do extenso e preguiçoso percurso de atualização cultural imposto à região é somente a partir de século XIX, que se torna possível discutir a atualização da imagem de Manaus e de seus costumes. A região passará oficialmente para a Coroa portuguesa somente na segunda metade do século XVII, quando em 1850 foi assinado o Tratado de Madrid entre a Espanha e Portugal. A partir desta data é possível vislumbrar uma política de lusitanização da região, orientada pelas ideias do marques de Pombal.

As medidas introduzidas pelo governo português demonstravam grande interesse em ocupar e controlar o extenso território amazônico. Dentre outros aspectos, essa lusitanização da cultura local significava, também, o estabelecimento de uma política de branqueamento. Em Lei de 15 de junho de 1752, o Conselho Ultramarino retomava a provisão de 1727 e ordenava que os missionários ensinassem os índios a falar, ler e escrever a língua portuguesa. A emissão da Carta Régia, em 3 de março de 1755, demonstra a intenção de ocupar efetivamente o território. Através deste documento, a região foi subdividida, criando-se a Capitania de São José do Javari, que, dois anos depois, passou a denominar-se Capitania do Rio Negro, administrada por um governador subalterno ao governador e capitãogeneral do Estado do Pará. A capital da nova capitania ficou sediada na aldeia de Mariuá, que, em 1758, foi promovida a vila e passou a denominar-se Barcelos (AVELLAR, 1976, p. 155) e (BAENA, 1839, p. 135).

Em 25 de junho de 1833, o Conselho Geral da Província do Pará (Divisão das Comarcas - Sessão do Conselho Geral da Provincia do Pará de 25 de junho de 1833.) retoma a questão dos limites da região e divide a província em três comarcas, a do GrãoPará, a do Baixo Amazonas e a do Alto Amazonas. A última compreendia os termos das Vilas de Manáos, Luzêa, Tefé e Mariuá. O artigo 27 desse documento determinava que $O$ Lugar da Barra do Rio-Negro fica erecto em Villa com a denominação de Manáos, servindo de cabeça do Termo.

Ao iniciar a segunda metade do século XIX, algumas cidades europeias experimentavam grandes transformações em virtude do processo de industrialização e das reformas urbanas. A implantação de políticas públicas de 
saneamento e a instalação de equipamentos e serviços públicos evidenciavam um claro compromisso com os discursos do progresso e da modernidade. Enquanto a vila de Manaus fora recém-promovida à condição de cidade com a denominação de Barra do Rio Negro e em 1850 se tornava capital da província do Amazonas. Ainda que ocupasse a significativa condição de capital da província do Amazonas se mantinha como um povoado muito pequeno, de aspecto bucólico, praticamente isolado no meio da selva amazônica, afastado dos grandes centros de civilização.

Mesmo considerando todas as limitações materiais que marcaram a ocupação e o desenvolvimento da região, é possível prever que a nova situação do lugar implicaria em um processo de mudanças, não somente do ponto de vista político e administrativo, mas, sobretudo, no plano cultural. Contudo, o que se observa é que somente após a instalação da província em 1852, é que se inicia um lento processo de transformação não somente dos aspectos materiais, mas também costumes locais.

A topografia da cidade era bastante acidentada, recortada por igarapés e ondulada por morros e ladeiras. Os bairros eram compostos por poucas ruas, em geral, curtas e irregulares. As casas erguiam-se sem muita regularidade sobre colinas ou se espalhavam nos limites desenhados pela sinuosidade dos igarapés que serpenteavam pela cidade e determinavam os limites dos bairros. Sobrados bem construídos se misturavam aos casebres cobertos com palha. Em geral, as construções eram feitas com material da região, tal qual a madeira, a palha, a pedra e o barro.

Ao se instalar, o primeiro presidente João Batista de Figueiredo Tenreiro Aranha apresentou um relatório, no qual situava o estado em que encontrou a capital da nova província, sobretudo, a precariedade material de suas construções. O relatório de Aranha encaminhado à Corte relatava as dificuldades encontradas e solicitava verba para algumas obras, justificando as necessidades locais. O primeiro presidente inaugurava um padrão de discurso oficial, cuja aplicação se prolongou até o final da monarquia.

A documentação oficial referente às obras públicas, na Província, encontra-se permeada de solicitações, críticas e lamentos. Muitas vezes, os administradores lamentavam que além da falta de verbas, houvesse a carência de materiais e de mão de obra. Propunham o emprego de diferentes alternativas, para superar as dificuldades, e alegavam que mesmo uma pequena obra, na capital da Província do Amazonas, se tornava muito mais cara e demorada que 
em qualquer outro ponto do Império. Além disso, as limitações econômicas não permitiam grandes investimentos para a realização das obras requisitadas. Nestas condições, é possível deduzir que, em suas primeiras décadas, a intervenção da administração pública da Província do Amazonas tenha ficado relegada mais a um papel legislador e controlador do que de realizador do projeto.

Sob as condições descritas, torna-se possível projetar uma imagem figurada da capital da Província do Amazonas, interpretando-a como uma das filhas do Império, esquecida nos confins e que, de acordo com o ditado popular: era pobre, feia e morava longe. Em matéria de obras públicas, apesar do aparente esforço de alguns administradores, pouco fora realizado na Província do Amazonas, cuja capital exibia poucos exemplares da arquitetura tradicional.

Pela descrição feita por vários viajantes que passaram pela região é possível deduzir que por todo o período provincial a cidade manteve praticamente a mesma aparência pitoresca que demonstrava o pequeno investimento aplicado em obras públicas. Contudo, podemos afirmar que a ordenação e configuração da cidade, com seu aspecto singelo e natural seguiam um padrão típico das cidades portuguesas construídas na América, segundo a concepção de Sérgio Buarque de Holanda (1969, p. 76). Para ele esse tipo de cidade não é produto mental, não chega a contradizer o quadro da naturez̧, e sua silhueta se enlaça na linha da paisagem. Nenhum rigor, nenhum método, nenhuma previdência, sempre êsse significativo "desleixo". Deve-se observar que o uso da palavra "desleixo", utilizada por Sérgio Buarque de Holanda, é uma referência direta à obra de Audrey Bell, Portugal of the Portugueses, na qual o autor considerou-a tão tipicamente portuguesa quanto a palavra saudade.

No Dicionario topografico, bistórico, descritivo da Comarca do Amazonas, de Lourenço da Silva Araújo Amazonas (1852, p. 190), consta que a população da cidade de Barra era de 8.500 almas, das quais 900 eram brancos, 2.500 mamelucos, 4.080 nativos índios, 640 mestiços de negros com índios e 380 negros escravos. De acordo com esta estimativa, havia uma clara preponderância da população indígena ou de origem nativa. Mas isto não significava uma uniformidade cultural, considerando-se que grande parte dessa população pertencia a diversas nações indígenas, sendo, portanto, falantes de diferentes troncos linguísticos.

Muitos dos habitantes da região ainda não dominavam a língua portuguesa e isto se constituía num grande obstáculo para a civilização dos indios, conforme 
observou Avé-Lallemant (1980, p. 116). Segundo o autor a civilização vestiu o tapuia em Manaus, mas observou também que os verdadeiros habitantes da mata não se sentiam à vontade, quando chegavam vestidos à cidade. Mas ressaltava que da civilização os índios adotaram tudo que thes é cômodo, com exclusão do que implica qualquer processo de trabalho.

A maior parte das intervenções urbanas regionais era orientada pelo Departamento de Higiene e pela Repartição de Obras Públicas. Cabendo a esta última a realização e administração de grande parte das obras, ela assumia, portanto, um papel relevante na definição dos traços da cidade almejada. Ainda que as obras públicas, em Manaus, tenham sido retomadas em 1853, o regulamento da repartição responsável não satisfazia a seus administradores, que por quase duas décadas continuaram a solicitar sua reforma.

Em 1856 a cidade retomou a denominação de Manaus e se mantinha como capital provincial localizada na região mais distante da Corte e, para chegar a ela, era necessário empreender longas, lentas e nem sempre cômodas viagens fluviais; enfrentar os perigos da fauna, das moléstias e da hostilidade dos "selvagens". A pequena cidade mantinha-se cercada por um vasto e rico território, mas não dispunha de braços nem tecnologia para explorar suas riquezas naturais. Permanecia em condição de pobreza, sua população era rarefeita, enquanto que a agricultura quase nula e o comércio insignificante.

Quando passou por Manaus, em 1859, o médico alemão Robert AvéLallemant (1980, p. 102) confessou-se impressionado com o exotismo do lugar e se referiu à localização da cidade como lindamente situada, mas, ao descrever seus elementos, teve dúvidas se chamaria de ruas os meros lancos, términos, esquinas e interrupcões que subiam e desciam por toda a parte. Para o alemão, o Palácio dos Presidentes parecia mofar um tanto maliciosamente do seu nome e se sustinha sobre pés fracos. Avé-Lallemant demonstra um encantamento perante o alegre contraste apresentado pela cidade. Nota que:

Terras altas e baixas - casas nos oiteiros e à beira d'água sólidos edifícios em estilo europeu, primitivas casas tapuias de barro - ora rua, ora igarapé - ali uma estrada, aqui uma comprida ponte de madeira; junto à margem, um vapor; perto dele, uma canoa do Amazonas; numa porta, uma cara branca; bem perto daí, banha-se um menino fusco - e assim tudo gira, pára, anda e nada confusamente." (AVÉLALLEMANT, 1980, p. 100). 
Avé-Lallemant (1980, p. 100) observava que aos possíveis confrontos produzidos pelo encontro da cultura europeia com as culturas nativas, era ainda um "quadro" bastante pequeno, no qual as formas eram modestas, tanto do europeísmo, que avançava, quanto da floresta virgem, que se afastava. Observa o médico viajante que não havia ainda a intensa luta de vida e morte entre as forças poderosas antes agradável reconciliação dos diversos elementos.

Certamente essa diversidade cultural dificultava as tentativas de uniformizar e integrar a população indígena. Mas o estímulo maior a todos os esforços feitos, no sentido de "civilizar" o índio, residia, sobretudo, na tentativa de resolver a carência de mão de obra na região. Além disso, aderir à civilização branca significava assumir sua mentalidade e, por conseguinte, diminuir as resistências ao processo em curso.

Avé-Lallemant (1980, p. 104) nota que por toda parte faltam ainda escolas, professores etc, e faltarão ainda por muito tempo. Apesar das grandes dificuldades observadas, ressalta o grande esforço de alguns pais em educar os seus filhos. Nota o autor que mães de boas famílias brancas cuidavam para que suas crianças, particularmente as meninas, tivessem uma educação e andassem vestidas. O médico alemão assegura que aprendiam música em casa e estudavam francês e italiano.

Alguns viajantes observaram com desconfiança o hábito de muitos brasileiros manterem suas mulheres e filhas longe dos olhares das visitas. Certamente não era regra geral, os mesmo viajantes assinalam a presença das mulheres nas missas, festas cívicas e religiosas, assim como em bailes dançantes. Certamente ao olhar feminino da americana Elizabeth Agassiz (1975, p. 167) foi permitido penetrar em recantos e interiores não acessados aos outros viajantes que transitaram pelo lugar. Ela pode penetrar em espaços mais íntimos da casa e da família e assim pode apresentar maiores argumentos para criticar a educação local e lamentar, principalmente, a condição da mulher brasileira. A autora observa que muitas passam meses e meses sem sair de suas quatro paredes e raramente se mostravam à porta ou às janelas de suas residências. Para a americana, era triste a existência dessas criaturas que, segundo ela, não tinham qualquer contato com o mundo exterior e viviam sem qualquer dos encantos da vida doméstica, sem livros, sem cultura de qualquer espécie.

Não havia um ambiente propício para o desenvolvimento de atividades culturais mais refinadas ou mais atualizadas, com exceção das inadequadas 
tentativas de reproduzir a moda do vestuário europeu e algumas formalidades sociais. Esse formalismo é indicado por Elizabeth Agassiz (1975, p. 174), ao observar que, mesmo nas grandes cidades brasileiras, reinava "certo constrangimento" na sociedade, que, segundo ela, acentuava-se nas cidades menores, onde para evitar qualquer erro, se exagera ainda mais no rigorismo das convenções sociais, concluindo que os brasileiros, com efeito, tão hospitaleiros e bons, são muito formalistas, enfatuados de etiquetas e cerimônias.

Compreende-se que a tentativa de reproduzir a aparência atualizada do vestuário significava mais que uma manifestação da futilidade ou da vaidade humana local. Esta prática pode ser interpretada como uma das evidências do desejo da sociedade local de integrar a civilização contemporânea, como se a vestimenta por si só fosse suficiente para integrá-los ao universo aspirado e capaz de estabelecer critérios de distinções e valores.

Sob outro ponto de vista, Avé-Lallemant (1980,p. 150) ressalta a existência de um grupo importante de brancos, em Manaus, que cuidava honestamentepara que sua raça não diminuísse de número. Entretanto, o autor nota que, mesmo entre os membros desse grupo, os traços indígenas se manifestavam, sobretudo, no rosto das mulheres mais velhas. Ele afirma que se podia falar de uma verdadeira sociedade de brancos em Manaus, muito agradável através do transluzir de indianismo. Esta observação do autor é mais um indicativo das tendências que se manifestavam no lugar e certamente os esforços despendidos neste sentido estavam comprometidos com ideais colonizadores, ou seja, estabelecer ou definir traços da cultura europeia. Contudo, as próprias informações emitidas por Avé-Lallemant, assim como as de Wallace, levam a inferir que as tradições de origem europeia não estivessem perfeitamente assimiladas e atualizadas na capital da Província do Amazonas.

Apesar de todas as dificuldades encontradas pela administração, subsistiam aspirações de reformular a cidade por uma imagem idealizada, mais de acordo com as ideias que se expandiam pelo mundo ocidental, contudo, o mais simples projeto era inviabilizado por limitações de ordem financeira. As argumentações apresentadas pelos presidentes que assumiram a província indicam a valorização de uma imagem mais de acordo com as noções de "civilização" e "higiene", elementos que constituíam a base das reformas urbanas do século XIX, e que sustentavam os discursos comprometidos com o progresso e a modernidade. 
Havia uma grande distância entre o que apresentava a realidade local e a imagem idealizada de uma cidade saneada e embelezada. Além dos aspectos materiais se fazia necessário adequar os hábitos e costumes locais às exigências citadinas que impunham não somente pelo crescimento da povoação, mas pelas mudanças propostas pela nova era que se apresentava plena de propostas. Sem dúvida, se tratava de intervenções muito mais difíceis e delicadas para realizar, considerando que as inovações propostas por determinados grupos se confrontavam com a tradição e com os traços da cultura material manifesta por diferentes segmentos da população local.

Sendo a cidade o receptáculo de múltiplas tendências, seus espaços repercutem e configuram os desejos dos homens, suas lutas psicológicas, sociais e religiosas, gerando um amplo território de tensão. Esses espaços de relações tensas favorecem a sobreposição de algumas tendências sobre outras e, assim, definem as características dos espaços da cidade. Esse arranjo temporário configura a forma da cidade e os interesses que se confrontam em seu interior.

A cidade, como obra, materializa os sonhos, os desejos e a imaginação de seus usuários, expressando-se no sentido da virtude humana, orientandose pelas aspirações de progresso e de modernidade da civilização. Numa concepção platônica (PLATÃO, 2002, p. 260), a virtude segue em direção à ideia do bem, aquilo que o filósofo afirmou se adquirir com dificuldade, no mundo inteligível. Para Platão, ela é a causa de tudo o que de reto e belo existe em todas as coisas; no mundo visível.

Como pretensa herdeira das tradições europeias, a elite local e seus governantes perseguiam uma imagem atualizada e mais de acordo com as aspirações de civilização. Promover a atualização dessa imagem significava, portanto, a adoção de modelos europeus. Todavia, a precariedade das condições financeiras e as limitações técnicas e culturais se constituíam em grandes barreiras para a concretização de tal aspiração. Não havia recursos suficientes para financiar grandes obras, nem a disponibilidade de mão de obra e de técnicos especializados que pudessem realizá-las. A imagem da cidade se encontrava sempre aquém das expectativas de seus idealizadores, gerando uma predisposição para adotar as propostas de renovação.

Compreendemos que as escolhas feitas por determinado grupo, nem sempre refletem suas necessidades reais, invariavelmente evidenciam acertos articulados por jogos de interesses e aspirações, nem sempre conscientemente 
refletidas ou assumidas pelos agentes que as negociam e executam. Contudo, mesmo contrariando a fala de seus discursos conservam algumas práticas de longa tradição.

As relações das cidades com as florestas mereceram inúmeros estudos que remontam o problema desde a Idade Média, colocando as cidades como o lugar da segurança e da virtude humana e a floresta com a ameaça e a insegurança ameaçadora do desconhecido. Aspectos dessa história de longa duração se repetem na ocupação da Amazônia e na criação das cidades da região. Não sendo amistosa a relação entre o homem e a natureza que o cerca. Por temor ou dominação procuram mantê-la cada vez mais afastada de seus centros de civilização. A mesma natureza que oferecia materiais, alimentos e braços para o trabalho também dificultava o projeto de ocupação e transformação.

Ansiosos por transformar as novas terras num imenso Portugal, os invasores estabeleciam um confronto frontal com a natureza e as tradições locais. Agrediam e modificavam, não somente o meio ambiente, mas também os nativos, condenando e subestimando suas práticas por não se adequarem ao projeto que aspiravam implantar. Contra a vontade, os nativos eram retidos em povoações, onde deviam se submeter a uma série de convenções sem qualquer sentido para a história de sua cultura ou para a sua realidade.

As tentativas de urbanizar e ordenar os espaços da cidade de Manaus na segunda metade do século XIX se tornava um pouco mais complexa que aquelas experiências adotadas no meado do século XVIII. Ainda que a maior parte de seus habitantes fosse descendente direta dos índios, a população já constituía um grupo muito mais miscigenado e apresentando uma certa unidade cultural, graças a intensa miscigenação que ocorrera na região e pode-se afirmar que se encontravam inseridos e integrados a um processo de civilização e urbanidade, orientado pelos padrões ocidentais.

Mesmo que consideremos que praticamente todos os presidentes designados para dirigir a província do Amazonas fossem procedentes de outras regiões do País e apresentassem algumas diferenças dos hábitos locais, estas diferenças podem ser consideradas relativas e pequenas se comparadas com os intensos choques culturais provocados pelos encontros e desencontros entre índios e portugueses. Entretanto, alguns aspectos das relações de autoridade e hierarquização se mantinham vivos e perfeitamente articulados com as tradições mais antigas. 
A administração controlada por um poder central, muitas vezes, gerava a reprodução de práticas sem qualquer relação com a realidade local. Um exemplo típico desta prática eram as propostas de arborização da cidade. Mesmo dispondo da mais variada coleção de espécimes vegetais, os administradores locais propunham o plantio de palmeiras imperiais, que não sendo nativas da região, sua aquisição implicava em grandes investimentos e sua conservação exigia maiores cuidados.

Políticas públicas adotadas por diferentes segmentos apresentam medidas de tendências contraditórias. Recomendações de aterramentos dos cursos d'água são frequentes como profilaxia recomendada pela higiene pública, por outro lado, é possível observar que os códigos de posturas apresentam vários artigos de proteção e conservação de recursos naturais da região.

É notória a insatisfação dos administradores perante a imagem da cidade de Manaus. Frequentemente, seus discursos revelam frustrações diante das dificuldades encontradas. Compreende-se que, com a permanência de determinados aspectos da paisagem, impossibilitava-se a adequação de sua imagem aos requisitos necessários a uma capital provincial. Não compunha um cartão de visita apropriado. O recorte natural da cidade era desenhado pelos leitos dos igarapés que a dividiam, mas esta característica era considerada inconveniente, pois além de impedir a regularidade das ruas e a comunicação entre os bairros, os igarapés comprometiam as pretensões de apresentar Manaus através de uma imagem saneada e higiênica.

Em determinados períodos do ano, a irregularidade natural dos leitos dos igarapés que cortavam a cidade contribuía para a estagnação de águas que, misturadas ao acúmulo de lixo produzido pela população, gerava uma aparência desleixada. Na época, apontavam-se os igarapés como o principal foco das emanações palustres e as teorias vigentes levavam a apontá-los como uma das principais fontes de miasmas.

Empreender obras para aterrar igarapés e outros cursos d'água ganhava destaque entre as obras públicas, a partir da orientação veiculada pelo governo central. Em um relatório emitido em 1853, por Francisco Gonçalves Martins, Ministro e Secretário dos Negócios do Império, (1853, p. 56) ao tratar de Melhoramentos sanitários na Capital e n'outras povoações do Império, observa-se que, nas províncias, havia poucos empreendimentos nessa área, apezar das instantes recommendações do Governo na providente Lei N. ${ }^{\circ} 598$ de 14 de setembro de 1850. 
Entretanto, o documento ressaltava que, na Província do Pará, continuava a obra do estacamento das vallas da Capital para o deseccamento dos terrenos alagadiços a ellas adjacentes.

O ministro do Império comunica que o Governo aguardava o detalhado orçamento que exigiria da obra do deseccamento do pantano entre as Cidades de Olinda e do Recife. Dentre as obras realizadas o ministro menciona o trabalho do presidente da Bahia para continuar a canalização do rio Camorogipe, que alagava os campos dos arredores da cidade, pois era uma das causas principais das febres intermitentes que perseguião e mesmo ceifavão a população em certas estações do anno.

As exposições do Ministério dos Negócios do Império não eram somente sugestões ou indicativos da política nacional, mas pretendiam determinar e orientar o uso dos espaços públicos e das práticas sociais. Entretanto, um dos grandes obstáculos para adotar algumas das práticas sugeridas era a precariedade das condições financeiras de muitas províncias.

A ocupação humana na região, com raras exceções, ainda hoje, é caracterizada pela degradação do meio ambiente. Iniciando com desmatamento da área, nivelamento do terreno, aterramento dos cursos d'água e utilização de variados materiais que agridem os aspectos naturais da paisagem e o próprio homem. A agressividade do contato, em geral, se encontra comprometidas a interesses imediatos e de caráter financeiro. Como se a manutenção da natureza representasse um comprometimento com o incivilizado e com um passado indesejado, no qual o homem e sua tecnologia apresentassem aspectos frágeis por se encontrarem a mercê de sua força poderosa.

Além disso, a substituição da paisagem natural por uma aparência mais urbanizada estava carregada de significados simbólicos - da criação de um espaço capaz de promover a melhoria na qualidade de vida de seus habitantes, com maiores garantias de segurança e passível de controle, demonstrando, sobretudo, um avanço da civilização sobre a barbárie.

Para compreender o sentido do termo civilizado, recorremos ao estudo de Nobert Elias que identifica a primeira evidência da evolução semântica do verbo civilizer para o conceito de civilization, na obra de Mirabeau, datada de 1760, cuja transcrição:

Maravilho-me de ver, como nossas opiniões cultas, falsas em todos os sentidos, se enganam no que consideramos ser 
civilização. Se perguntar o que é civilização, a maioria das pessoas responderia: suavização de maneiras, urbanidade, polidez, e a difusão do conhecimento de tal modo que inclua o decoro no lugar de leis detalhadas: e tudo isso me parece ser apenas a máscara da virtude, e não sua face, e civilização nada faz pela sociedade se não the dar por igual a forma e a substância da virtude.

Para Elias, tanto Mirabeau quanto Kant vinculam o conceito de civilização às características especificas da aristocracia de corte. $\mathrm{O}$ autor explica que essa vinculação ocorre, porque l' homme civilisé nada mais era do que uma versão ampliada daquele tipo bumano que representava o verdadeiro ideal da sociedade de corte, o honnête homme. Quanto ao termo civilisé, o autor observa que não raro era utilizado como sinônimo de cultivé, poli, ou policé, significando um comportamento refinado que, por comparação, se contrapunha às maneiras dos indivíduos mais simples e socialmente inferiores.

O uso dos manuais, nas cortes europeias, definia as convenções de comportamento social e implicava a adoção de um código. A aceitação dos membros na corte, assim como a sua circulação nos "espaços civilizados", dependia do domínio deste código de etiquetas. Através de sua decodificação, detectavam e incluíam os "civilizados" e excluíam os "incultos". Elias interpreta esse controle através de normas como um artifício, para consolidar o modelo de civilização que estava sendo implantado.

Alguns presidentes da Província do Amazonas demonstravam especial atenção com o melhoramento da capital, cientes de que a imagem da cidade era capaz de demonstrar o nível de civilização da população instalada. Frequentemente, manifestavam insatisfação perante a aparência da cidade, cujos traços pouco refinados evidenciavam os rudimentos da cultura local. Em contrapartida, eles propunham uma série de melhoramentos, cuja realização corresponderia à construção da imagem desejada, com base em modelos de modernidade de países europeus.

Até o final da monarquia. a sociedade instalada em Manaus era movida por acontecimentos de uma lenta temporalidade, e a introdução de inovações materiais era muito tímida. As regras comportamentais da sociedade sofriam poucas alterações, devido ao isolamento geográfico e cultural. Sendo assim, o conjunto composto pelas narrativas dos viajantes apresenta uma diversidade 
de desenhos do mesmo espaço, sugerindo mudanças em diferentes elementos de sua paisagem natural, urbana e social.

Um dos principais recursos adotados pela administração pública da província do Amazonas, no século XIX, foi a elaboração e aplicação dos Códigos de Posturas Municipais. O conteúdo didático desses documentos, assim como o seu caráter normativo, pode ser interpretado como uma cartilha dos costumes na cidade, cuja função era orientar o processo civilizador. A concepção de um instrumento capaz de guiar a construção de uma imagem da cidade, ordenando os espaços e o comportamento de seus usuários, remete diretamente ao estudo de Nobert Elias (1994, p. 54) sobre os manuais de etiquetas como reguladores do comportamento das cortes europeias.

As características das normas de controle aplicadas em Manaus, na segunda metade do século XIX, assim como sua relação com os hábitos da população, denotam o alcance da intervenção impetrada pelo Estado, que demarcou o seu domínio, ampliando com maior precisão os limites do espaço público, ao mesmo tempo em que restringia os espaços privados. Essas tendências apresentam grandes similitudes com as práticas de controle adotadas pelas cortes europeias, principalmente no que pode ser interpretado como mais um artifício para consolidar um modelo de civilização.

Outro importante aspecto da discussão sobre o comportamento "civilizado" é considerado por Elias (1994, p. 16) como a inter-relação da estrutura do comportamento civilizado com a organização das sociedades ocidentais sob a forma de Estado. $\mathrm{O}$ autor discute o fenômeno da descentralização que abalava a sociedade medieval europeia, assinalando como o território governado por numerosos guerreiros se tornou uma sociedade mais ou menos pacificada.

Ainda que tardiamente, era esse mesmo processo que se implantava na Amazônia, no século XIX. O Brasil se estruturava sob a forma de um Estado monárquico e suas ideias expandiam-se por todo o território nacional. A tradição guerreira dos povos amazônicos fora dizimada, perante a violência do processo de colonização e ocupação da região. Apesar de vencidos pela força, esses povos resistiam, quer no predomínio étnico da população, quer nos traços da cultura local. Contudo, essas manifestações nativas não passavam despercebidas pela estrutura de Estado instalada na Província.

Em consequência da situação geográfica e econômica, o Amazonas mantinha sua reduzida população culturalmente isolada. Foi somente no século 
XIX, por questões políticas, que o Império brasileiro ensaiou implantar algumas medidas para efetivar a ocupação da Amazônia, integrando-a definitivamente ao território nacional. Entretanto, foi apenas nas últimas décadas daquele século, em virtude da exploração da borracha, que o processo de ocupação e "ocidentalização" da Amazônia tornou-se mais evidente através da aparência de suas capitais.

As intervenções feitas pelo Estado estavam estruturadas em um modelo de discurso hegemônico. Seus representantes reproduziam e assumiam procedimentos idealizados e aplicados em outras realidades completamente diferenciadas da que encontravam na Amazônia. Nota-se, entretanto, que a formulação de determinadas propostas proibitivas visava, especificamente, a costumes locais.

A figura do presidente da província representava o ponto mais alto da hierarquia administrativa provincial. Em geral, os ocupantes dos cargos administrativos mais elevados eram enviados pela Corte Imperial, eram originários de outras regiões do País. Seus discursos constituíam uma das principais manifestações da estrutura de Estado e, muitas vezes, evidenciavam as ideias políticas e administrativas que os colocava como os representantes da civilização.

Em geral, os discursos presidenciais sugerem uma conscientização do papel de seus autores como administradores de um "projeto civilizador". Suas ideias orientavam o corpo administrativo da região e davam continuidade ao processo de civilização que pretendiam implantar. As atividades deste corpo administrativo estavam regulamentadas, assim como os instrumentos normativos que aplicavam à sociedade, legislando e fiscalizando o uso dos espaços e das ações dos cidadãos. Este controle do espaço se justificava pelas questões da ordem e da segurança públicas. Ampliava a ação do Estado como o ordenador e modelador da cidade. No entanto, esta ação estava amplamente apoiada por um discurso comprometido com as ideias de progresso e modernidade.

O poder público tentava impor controle através dos recursos normativos. Estabelecia e aplicava códigos, leis e outras punições, como multas e prisões, a fim de reprimir determinados comportamentos considerados inadequados para os padrões de "civilização". As manifestações populares passaram a ser interpretadas como expressões não "civilizadas" e pouco "polidas", devendo, portanto, ser inibidas.

Ao discutir as mudanças urbanas processadas no Rio de Janeiro, durante o século XIX, Chiavari (1985, p. 586), Lilian Fritsch e Sérgio Pechman (1985, 
p. 147) indicam o surgimento do primeiro Código de Posturas Municipais do Rio de Janeiro em 1832, entretanto Ernesto Cruz (1952, p. 484) menciona que o primeiro Código de Posturas de Belém, sob a forma de manuscrito, data de 1831. Provavelmente os códigos de posturas aplicados nas províncias brasileiras derivam do primeiro código do Rio de Janeiro, de onde emanava o poder da Corte. O conteúdo normativo desse documento estende o poder de controle do Estado e regula praticamente todas as atividades da sociedade, determinando dispositivos de natureza higiênica e de comportamento social. Os códigos de posturas eram compostos por diferentes rubricas e abrangiam os mais variados temas relativos à cidade e as relações de convivência e uso. Do embelezamento da cidade à conservação da paisagem natural de seus arrabaldes, da venda e conservação de alimentos ao comportamento social e lazer da população, esse código passou a ser reproduzido, praticamente na íntegra, e sua promulgação era feita pelo presidente da província.

Talvez pela abrangência e importância que assumia para a administração pública, o primeiro tema tratado pelo Código de posturas municipaes de Manáos, de 1872,(Colleção de Leis da Assembleia Provincial do Amazonas. 1872) era o "Aformoseamento e regularidade da cidade e suburbios". Em seu artigo 3.', proibia a "edificação de casas cobertas de palha", sob pena de se demolir a obra em conta de quem a realizasse, impondo-se ainda ao proprietário a multa de trinta réis ou oito dias de prisão. A área delimitada por este artigo abrangia as ruas dos Remédios, Boa-Vista, Espírito Santo, Marcílio Dias, Flores, Imperador, Brazileira, Manáos (até o Aterro), Henrique Martins, Cinco de Setembro, São Vicente, Independência, assim como as travessas que lhe eram correspondentes.

O conteúdo desse artigo pode ser analisado, pelo menos, por dois pontos de vista: a proibição pretendia excluir de suas ruas centrais os aspectos mais comprometidos com os traços nativos e retirar dos centros urbanos as classes mais pobres da sociedade. Essa medida, adotada também em outras cidades brasileiras, pretendia estabelecer um centro urbano de aparência europeia. Sua inclusão nos códigos era o reflexo de uma política inspirada nos espelhos, ou seja, pretendia-se organizar e orientar a sociedade tropical, a partir de padrões europeus. Em síntese, as intervenções pretendiam promover a civilização, o que, em outras palavras, significava um processo de "branqueamento", no qual a imagem da cidade ganhava destaque especial. Por outro lado, compreende-se que essa normatização visava atender a 
exigências naturais do crescimento dos centros urbanos e à necessidade de reduzir as possibilidades dos devastadores incêndios, propiciados pelas construções em palha e madeira, constituindo-se tal fato numa medida de segurança para a sociedade.

A adoção desse conjunto de práticas diferenciadas revela um claro distanciamento da tradição, que, segundo a concepção de Sérgio Buarque de Holanda (1969, p. 62), teria orientado a formação das cidades brasileiras. O Estado brasileiro adotava, em certa medida, a mesma orientação que séculos antes fora implantada nas cidades espanholas na América: uma atitude mais racional em relação à ocupação e uso do espaço urbano, cuja rigidez de traçado é interpretada pelo autor como um reflexo da disciplina imposta pela mão forte do Estado. Segundo ele, as ruas não se deixam modelar pela sinuosidade e pela aspereza do solo; impõe-lhe antes o acento voluntário da linha; denuncia o esforço determinado de vencer e retificar a natureza caprichosa da paisagem agreste: é um ato definido da vontade bumana. Todavia, Holanda ressalta a importância de uma abundante legislação, com a finalidade de manter o traçado retilíneo e prevenir qualquer fantasia $e$ capricho na edificação dos núcleos urbanos.

O Estado assumia o controle de vários outros aspectos da edificação, inclusive características formais. O 1. ${ }^{\circ}$ artigo do título Aformoseamento da cidade, aprovado pelo Codigo de Posturas da Câmara municipal de Manáos de 1875 (Lei 336 de 29 de maio de 1875), proibia edificar ou reedificar predio, cerca ou muro dentro da cidade sem previa licença e alinhamento dado pela Camara Municipal. A alínea 1. desse artigo determinava que a fachada dos edifícios térreos devesse medir mais que cinco metros de altura, enquanto que a dos sobrados, nove metros de altura. Exigia-se que os portais deveriam medir mais de três metros de altura e as janelas, dois metros e dez centímetros, sobre um e cinco de largura. A alínea 2. a do mesmo artigo determinava que o desenho do edifício a ser construído acompanhasse a solicitação "alinhamento" para ser aprovado pela Câmara.

A formulação dealguns artigos sugerequetaisinstrumentos normatizadores fortaleciam o controle exercido pelo Estado e expandiam os limites do espaço público, penetrando no universo privado, através da regulamentação do espaço e do controle do corpo. Mostra também que, em alguns casos, conciliava os interesses com certas atividades capitalistas irregulares, mas toleráveis, como a construção dos criticados cortiços. Em uma demonstração da hipocrisia dessas normas, pode-se citar o artigo 2. ${ }^{\circ}$ do Código de Posturas de 1875, que proibia a construcção de casebres ou pequenos quartos, no perímetro urbano da cidade, sem 
que os donos ou possuidores de terreno levantem no alinhamento um muro simulando casa e apresentando as alturas estabelecidas na alínea $1 .^{a}$ do $10^{\circ}$ artigo.

A valorização de determinados padrões estabelecidos para a fachada das edificações, assim como a rejeição a determinados materiais naturais como a madeira e a palha, típicos da arquitetura popular local ressaltam, em certa medida, o artificialismo do processo e remete a intervenções promovidas em São Petersburgo, durante o século XIX, cujas intervenções foram analisadas em profundidade por Marshal Berman em Tudo que é Sólido Desmancha no Ar: a Aventura da Modernidade (1987). O autor ressalta o vitrinismo impregnado em todo o processo de modernização, ressaltando a distância entre os padões adotados e os traços culturais da cultura local, destaca ainda, a proibição do uso de materiais e formas tradicionais comprometidos com a cultura russa.

$\mathrm{Na}$ ausência de maiores argumentos para impor os códigos de posturas, as autoridades pressionavam e penalizavam infratores com multas e prisões. Quanto ao uso dos espaços urbanos, destacam-se alguns artigos do código de 1872 (Coleção das Leis da Província do Amazonas, 1872, .p. 107; 109, 115, 116; 125): multa de cinco mil- réis aos donos de carros ou carroças que chiarem pelas ruas ou praças da cidade; não era permitido soltar nas ruas da cidade o fogo de artifício denominado busca-pé; não podiam assoalhar-se as roupas às janelas, ruas e praças, armar cordas para estendê-las nos mesmos lugares, bem como lavá-las nos igarapés que cortam esta cidade; ninguém poderia disparar armas de fogo dentro da cidade e suburbios, bem como flechas, não era permitido retirar água do igarapé do Aterro, para vendê-la à população; seria multado em 20 mil- réis ou preso por quatro dias todo aquele que insultar com palavras ou acções a qualquer pessoa; pagaria cinco mil- réis ou seria preso por um dia quem gritasse ou fizesse alaridos, voseria, assuada e correria nas ruas, praças e estradas, que não fossem para pedir ajuda ou capturar criminoso

Algumas infrações, quando cometidas à noite, tinham suas penas dobradas. O valor da multa seria de cinco mil-réis, ou dois dias de prisão, para a pessoa que andasse embriagada pelas ruas, sendo a prisão "aplicada em dobro" àqueles que não tivessem meios para pagá-la; quem fosse encontrado escrevendo ou fazendo dísticos, figuras indecentes ou colocando pasquim e escritos imorais, em qualquer lugar, seria multado em 30 mil- réis ou pegaria oito dias de prisão; era proibido andar semi-nú ou indecentemente vestido pelas ruas, praças e estradas da cidade, assim como, lavar roupa e animais no seo litoral e igarapés que o cortão, ou próximo das fontes que fornecem água para o consumo público. Para essas últimas infrações, era cobrada uma multa de dez mil- réis ou três dias de prisão. 
Um dos artigos do código de posturas da Câmara Municipal de Manaus, aprovado pela Lei 534, de 3 de junho de 1881(COLLEÇÃO DE LEIS DA PROVÍNCIA DO AMAZONAS. 1881, p. 6), proibia qualquer pessoa de banhar-se núa dentro do litoral e nos igarapés que o cortam, das cinco da manhã às seis e trinta da tarde, ficando o infrator sujeito a multa de vinte mil- réis ou cinco dias de prisão. Na prática é possível prever grandes dificuldades na aplicação de normas de comportamento proposta por códigos estabelecidos pela moral citadina de outras plagas. As tradições e os hábitos cotidianos, muitas vezes inconscientes, se impunham de forma contundente, uma resistência de traços da cultura indígena e miscigenada já estabelecida e que de alguma forma podem revelar muitos traços da população local. Mas é provável que parte destas normas aplicadas não tenha exercido grande pressão sobre os hábitos locais, tais como estender roupa para secar em lugares não permitidos; ou tomar banho nu no litoral e igarapés da cidade, além de muitos outros que persistiram e se mantiveram, mesmo no século XX.

A proibição de banhar-se despido nas águas urbanas, no mar, no rio ou no igarapé era comum aos códigos de Belém e do Rio de Janeiro. Todavia, em Manaus, era possível que sua aplicação fosse muito difícil perante as resistentes tradições indígenas. Ao descrever um de seus passeios nos arrabaldes da cidade, em 1865, Elizabeth Agassis (1975, p. 175) destaca a presença de dois índios despidos sobre troncos de árvores, pescando com arco e flecha, no igarapé da Cachoeira Grande.

Alguns mais rígidos que outros, os códigos determinavam das características da morada aos modos de comportamento. As normas estavam impregnadas de princípios moralizadores e suas proibições pretendiam impor uma ação transformadora, educando e polindo os costumes locais; em última instância, se redesenhava a paisagem urbana. O conjunto de normas constitui um discurso coerente e oficializa a orientação de certa moral. A proibição da nudez diurna na beira dos rios e igarapés da cidade colocava o corpo despido no mesmo plano dos casebres, que só podiam ser construídos por trás de falsas fachadas. Estes aspectos do discurso evidenciam a valorização da aparência externa das coisas, assim como das tradições europeias, e é uma clara rejeição às manifestações mais comprometidas com aspectos nativos ou populares, propondo, muitas vezes, padrões completamente inadequados ao clima quente e úmido da região.

A difusão das ideias emitidas na documentação oficial refletia diretamente os anseios da elite nacional. À administração pública atribuía-se 
um papel regulador, com a tarefa de aplicar e fiscalizar as normas. Esta posição evidenciava-se tanto nos discursos dos presidentes, quanto nos relatórios apresentados pelas várias repartições do Estado. Entretanto, havia outros atores executores que atuavam neste processo transformador. Destaca-se o relevante papel assumido pela imprensa e pela literatura, ora como orientadores, ora como observadores críticos. A educação, a moda e o consumo atuavam de maneira coadjuvante, mas a ação de todos estes segmentos da sociedade mostra uma vinculação direta com um discurso que se articulava em torno das ideias de uma civilização do progresso e da modernidade.

O otimismo e a predisposição com que o Estado recebia as ideias de progresso facilitavam grandemente o estabelecimento dos serviços de melhoramentos urbanos. Por outro lado, esse otimismo, estimulado por interesses comerciais, favorecia determinados grupos que se articulavam através de uma rede de influência, que se estendia no âmbito das políticas públicas e na opinião da imprensa. Assim, a aprovação de projetos e outras propostas de melhoramentos urbanos, muitas vezes, pode ser interpretada como mera manipulação de um jogo.

São frequentes, nos Anais da Assembléia Provincial, as leituras de propostas para os mais diversos serviços públicos financiados pelo Estado, contendo o nome do beneficiado para executá-las. Muitas vezes, as propostas apresentadas geravam debates acalorados entre os deputados e nem sempre se esgotavam com brevidade, como foi o caso da polêmica criada em torno da aprovação do projeto para a construção de um teatro em alvenaria em Manaus.

Os mais diversos projetos apresentados na Assembleia apoiavam-se em justificativas que os atribuíam como sendo do interesses da população e da cidade. Um exemplo significativo é a justificativa do projeto para a construção do teatro Amazonas, apresentada em 1881, pelo deputado Fernandes Júnior (Annaes da Assembléa Legislativa do Amazonas -1880-1881.1881.p. 80): considerando que sem haver edificio proprio não teremos representações theatraes, cuja distração é incontestavelmente de utilidade e muito concorre para a civilisação de nossa cidade.

Apesar de todas as limitações de ordem ambiental e cultural, a elite local investia no processo de transformação e são frequentes as sugestões para a execução de serviços ou formações profissionais orientadas pelo modelo europeu. A Lei 650, de 6 de junho de 1886 (COLEÇÃO DE LEIS DA PROVÍNCIA DO AMAZONAS - 1886. 1886. p. 39), autorizava o presidente a inovar ou rescindir 
o contrato da iluminação pública e substituí-la por um sistema de luz elétrica, tendo em vista os últimos aperfeiçoamentos obtidos na França e na Inglaterra por Luone e Uamoud ou outros cujos resultados produzidos tenham sido melhores. Em 16 de junho de 1887, o presidente era autorizado, pela Lei 762 (COLEÇÃO DE LEIS DA PROVÍNCIA DO AMAZONAS - 1887.1887. p. 100), a comissionar um cidadão com as habilitações necessarias para estudar na França, Bélgica, ou qualquer paiz da Europa ou da America, os melhoramentos mais applicados á boa organisação da instrucção publica.

A gênese das transformações urbanas processadas na cidade de Manaus, culminando com a grande transformação apresentada no final do século XIX, reproduz em diferente grau as características do processo "civilizador" implantado na Europa no final do século XV. Naquele momento, o Estado se estruturava como nação e sua ação centralizadora se manifestava de diferentes formas na configuração da cidade a partir do controle dos espaços públicos a partir de uma imagem ordenada e embelezada.

Ainda que em pequena proporção as mudanças processadas no lugar evidenciam a multiplicidade de imagens em diferentes temporalidades. Imagens que se superpõem em uma contínua tentativa de ocidentalizar a cultura nativa. Apesar das limitações para promover os melhoramentos requisitados e realizar grandes mudanças urbanas, a documentação oficial sugere que havia uma predisposição natural, no sentido de atualizar a imagem da cidade por traços mais modernos e "civilizados". A manutenção desta prática em Manaus sugere que o processo obedece à tradição de longa duração que acompanha o desenvolvimento natural das cidades.

\section{Conclusão}

As manifestações da sociedade local que, muitas vezes, chocavam alguns viajantes eram expressões espontâneas, sem o artificialismo das convenções de refinamento. Mantinham uma distância considerável dos hábitos que naquele momento se encontravam em voga nos centros culturais europeus. Eram próprias de uma população de origem predominantemente indígena que ainda não tivera tempo suficiente par assimilar o novo universo que fora imposto, mas, sob o autoritarismo das imposições, tentava dominar as representações e costumes brancos através da imitação. Compreende-se que a manifestação destas tendências de traços toscos eram expressões autênticas adquiridas através das duras condições 
em que se configurou. Certamente, a origem étnica e cultural dessa população fora um fator determinante das características que persistiam na cultura local.

Apesar de todos os questionamentos que possamos submeter os censos realizados no Brasil, durante o século XIX, da eficácia dos métodos de levantamento quanto à precisão das estimativas numérica, não há como ignorar o conjunto de observações e depoimentos emitidos por diferentes fontes, indicando uma predominância indígena na formação da população regional.

A origem da civilização instalada foi marcada por um processo de dominação brutal. Sob estas condições, é previsível que os traços adquiridos não revelassem características refinadas dos costumes, mas expressassem a vivência daquele grupo, revelando os aspectos mais rudes da herança européia e a perplexidade das origens nativas. Sua imagem, portanto, mantinha uma considerável distância das idealizações ocidentais contemporâneas, sobretudo pelas precárias condições financeiras da sociedade local. Compreende-se que a configuração da sociedade, assim como a imagem da cidade, expressava precisamente o tratamento recebido em seu processo de construção.

Compreende-se que as criticadas manifestações são características próprias da cultura branca e as limitações apresentadas não eram mais que o resultado natural de um processo de imposição cultural. Ao dominarem a região e escravizarem as nações indígenas, os portugueses fragmentaram e praticamente extinguiram o universo das culturas locais. Ao impor os seus padrões culturais, desqualificaram as expressões e os saberes nativos. Neste processo, os sobreviventes perdiam suas referências culturais e eram inseridos em um novo universo de representações, cujas convenções, muitas vezes, não eram decodificadas em sua integralidade ou se mantinham completamente incompreensíveis. Entretanto, sob a força da pressão não encontravam muitas alternativas, senão imitar.

A assimilação deste universo implicava um longo processo de reprodução e vivência, todavia, a imposição consciente da cultura portuguesa, com sua língua e seus costumes, encontrava grandes dificuldades, não somente pelas condições materiais do novo ambiente, mas, sobretudo, pelo contínuo confronto com variadas formas de resistência. Ainda que estas manifestações de resistência não se apresentassem como elementos de um processo consciente articulado e contraposto às inovações impostas. Não se pode negar a eficácia destas formas como responsáveis pela manutenção de determinados traços da cultura. Além das evidências apresentadas pelos hábitos alimentares e pelo ritmo de vida, 
outras manifestações eram preservadas também no plano imaterial, mantendose vivas e atuantes por necessidades que resistiam inconscientemente.

O padrão da cultura portuguesa sofrera uma série de restrições ao ser introduzido na região. O primeiro deles era, sem dúvida, o nível cultural elementar de seus representantes. Além da ausência de instituições sociais mais tradicionais, havia a necessidade de adaptação às limitações de ordem materiais impostas pelo meio ambiente que contribuíam para a defasagem cultural a que se ficava entregue. Por outro lado, a organização imposta desvalorizava quaisquer traços indígenas, identificando-os como manifestação de uma cultura indesejada, que deveria desaparecer. Assim, a sociedade local mantinha-se culturalmente afastada das origens étnicas, defasada e regulada por um padrão ultrapassado que não era inteiramente assimilado. A população, predominantemente mestiça, era composta principalmente de caboclos e índios destribalizados. Muitos desses elementos não experimentavam qualquer transição cultural, sendo inseridos abruptamente na convivência e ritmo da cidade. Portanto, as estreitas vinculações com os hábitos da floresta favoreciam um ritmo de vida mais lento e promovia o informalismo das relações sociais.

A ocupação e exploração da região foram processadas de forma rudimentar, priorizando práticas mercantis que saqueavam a riqueza local e oprimiam e escravizavam os nativos. O caráter empobrecedor destas relações, assim quanto o baixo nível cultural apresentado pelos indivíduos transplantados, não favorecia o desenvolvimento de atividades eruditas na região. Além do isolamento geográfico e cultural, as dificuldades materiais se acentuavam pela ausência mão de obra gabaritada em todas as áreas do conhecimento. Assim a natureza se impunha exigindo adaptações e determinando limites. Tais limitações estabeleciam um distanciamento considerável em relação a qualquer aldeia europeia.

\section{Referências}

AGASSIZ, Louis; AGASSIZ, Elizabeth Cary. Viagem ao Brasil: 1865-1866. São Paulo: Editora Nacional, 1975.

ANNAES DA ASSEMBLEIA LEGISLATIVA DO AMAZONAS - 18801881. Manáos: Tipographia do Amazonas, 1881.

ARAÚJO E AMAZONAS, Lourenço da Silva. Dicionario Topographico Historico Descritivo da Comarca do Alto Amazonas. Recife: Typographia Commercial. 1852 
AVÉ-LALLEMANT, Robert. No Rio Amazonas - 1859. Belo Horizonte: Editora Itatiaia; São Paulo: Ed. Da Universidade de São Paulo. 1980.

AVELLAR, Hélio de Alcantara. História Administrativa e Econômica do Brasil. Rio de Janeiro: Fename. 1976

BAENA, Antônio Ladislau. Ensaio Corografico sobre a Provincia do Pará. Pará: Typographia de Santos, 1839.

BERMAN, Marshall. Tudo que é Sólido Desmancha no Ar: a Aventura da Modernidade. São Paulo: Companhia das Letras, 1987.

BIARD, François Auguste. Dois anos no Brasil. São Paulo: Editora Nacional, 1945.

CHAVES, Vasconcellos. Relatório de 3 de março de 1886 do presidente da Província. Manáos: Typographia do jornal Amazonas, 1886.

CHIAVARI, Maria Pace. As Transformações Urbanas no Século XIX. In: . O Rio de Janeiro de Pereira Passos. Rio de Janeiro: PUC, 1985. (Coleção uma cidade em questão).

CORREAA, Luís de Miranda. Manaus: aspectos de sua arquitetura. Rio de Janeiro: Agência da Spvea, 1964.

CÓDIGO DE POSTURAS MUNICIPAES DE MANÁOS, de 1872. Manáos: Typografhia do Amazonas, 1872. (Colleção de Leis da Assembleia Provincial do Amazonas. Tomo XX).

COELHO, José Maria. Memória sobre a capitania de São José do Rio Negro. Revista do IHGB, v. 203, Rio de Janeiro, Departamento de Imprensa Nacional, 1948.

COLEÇÃO DE LEIS DA PROVÍNCIA DO AMAZONAS - 1886. Manáos: Typographia do Jornal do Amazonas, 1886. 
COLEÇÃO DE LEIS DA PROVÍNCIA DO AMAZONAS - 1887. Manáos: Typographia do Jornal do Amazonas, 1887.

COLLEÇÃO DE LEIS DA ASSEMBLEIA PROVINCIAL DO AMAZONAS. Manáos: Typografhia do Amazonas, 1872. Tomo XX, de 1872.

COLLEÇÃO DE LEIS DA PROVÍNCIA DO AMAZONAS. Manáos: Typographia do Amazonas, 1881. Tomo XXIV.

CRUZ, Ernesto. Procissão dos Séculos: vultos e episódios da história do Pará. Belém: sem editora, 1952.

DIAS, Satyro. Relatório do Presidente da Província do Amazonas de 1.0 de outubro de 1880. Manáos: Typographia do Amazonas, 1880.

DIVISÃO DAS COMARCAS - Sessão do Conselho Geral da Província do Pará de 25 de Junho de 1833.

ELIAS, Nobert. O Processo civilizador. Rio de Janeiro: Jorge Zahar Editores, 1994.

FABRIS, Annateresa. O Ecletismo à luz do modernismo. In . Ecletismo na Arquitetura Brasileira. São Paulo: Nobel/Edusp, 1987.

FORTES, Ernesto Mattoso Maia. Intinerário e Trabalhos da Commissão de Estudos da Estrada Madeira-Mamoré. Impressões de viagem por um dos membros da mesma. Rio de Janeiro: Soares \& Niemeyer, 1885.

FRITSCH, Lílian; PECHMAN, Sérgio. A Reforma Urbana e o seu Avesso: Algumas Considerações a Propósito da Modernização do Distrito Federal na Virada do Século. Revista Brasileira de História, v 5. n. 8/9, 1984/1985, São Paulo.

GIBBON, Ladner; HERNDON, Lewis. Exploración del Valle del Amazonas (Tomo I). Quito: Monumenta Amazônica, 1991

HOLANDA, Sérgio Buarque de. Raízes do Brasil. 5. ed. Rio de Janeiro: Livraria José Olympio, 1969. 
KELLER-LEUZINGER, Franz. The Amazon and Madeira rivers. Londres: Chapman and Hall, 1874.

MARTINS, Francisco Gonçalvez. Melhoramentos sanitários na Capital e n'outras povoações do Império. Rio de Janeiro: Typographia Nacional, 1853.

MARTIUS, Carl Friedrich; SPIX, Johan Baptist von. Viagem pelo Brasil: 18171820. Melhoramentos, INL, IHGB.

MATTOS, José Wilkens de. Relatório de 25 de marco de 1870. Manáos: Typographia do Amazonas, 1870.

MAW, Henry Lister. Journal of passage from the Pacific to the Atlantic crossing the Andes and dwon the Amazon and descending the river Maranon. Londres, 1829.

MESQUITA, Otoni Moreira de. Manaus: História e Arquitetura - 1852/1910. Manaus: Editora Valer, 1999.

PLATÃO. A República. São Paulo: Best Seller, 2002.

REIS, Artur César Ferreira. História do Amazonas. Manaus: Superintendência Cultural do Amazonas/ São Paulo: Edusp, 1989.

SOUZA, Francisco Bernardino de. Lembranças e curiosidades do Amazonas. Pará: Typographia do Futuro, 1873.

TOCANTINS, Leandro. Aspectos da arquitetura tradicional de Manaus. Revista do LAB, Rio de Janeiro: Arte Nova, Janeiro de 1964.

WALLACE, Alfred Russel. Viagens pelos rios Amazonas e Negro. Belo Horizonte / São Paulo: Itatiaia / Edusp, 1979.

110 Somanlu, ano 9, n. ${ }^{\circ}$ 2, jul./dez. 2009 